\title{
NMR Studies of Cation Induced Conformational Changes in Anionic Biopolymers at the Endothelium-Blood Interface
}

\author{
G. Siegel,${ }^{* 1}$ A. WAlter,${ }^{* 1}$ K. RüCKBORN,${ }^{* 1}$ \\ E. BUdDECKE, ${ }^{* 2}$ A. SCHMidT, ${ }^{* 2}$ H. GuStavsSON, ${ }^{* 3}$ \\ and B. LINDMAN*3 \\ ${ }^{* 1}$ Institute of Physiology, Biophysical Research Group, The Free University \\ of Berlin, D-1000 Berlin 33, Germany \\ *2 Institute of Physiological Chemistry and Pathobiochemistry, \\ The Westfälische Wilhelms-University, D-4400 Münster, Germany \\ ${ }^{* 3}$ Kemicentrum, Fysikalisk Kemi 1, Lunds Universitet, \\ S-22007 Lund 7, Sweden \\ (Received January 18, 1991)
}

\begin{abstract}
In the vessel walls, the connective tissue components surrounding the smooth muscle cells display a high binding capacity for small cations which has been ascribed to the presence of polyanionic proteoglycans. ${ }^{23} \mathrm{Na}^{+}$and ${ }^{39} \mathrm{~K}^{+}$NMR measurements indicate that, while monovalent cations exert merely competitive interaction, divalent cations induce a conformational transition changing specifically the affinities for other ion species. $\mathrm{Mg}^{2+}$ or $\mathrm{Ca}^{2+}$ ions cause such a configurational change in the physiologic concentration range which promotes allosteric, cooperative binding of $\mathrm{K}^{+}$or $\mathrm{Na}^{+}$ions, respectively, to vascular connective tissue. The geometry of narrow tissue clefts in the interstitial compartment of the vessel wall entails that an increase of extracellular $\mathrm{Mg}^{2+}\left(\mathrm{Ca}^{2+}\right)$ concentration effects a decrease of external $\mathrm{K}^{+}\left(\mathrm{Na}^{+}\right)$concentration in the vicinity of vascular smooth muscle cell membranes. Membrane hyperpolarization and vasorelaxation is the result.

Proteoglycans are viscoelastic, anionic biopolyelectrolytes which consist of many highly sulphated and carboxylated glycosaminoglycan chains that are covalently attached to the protein core. The physicochemical and functional properties of the proteoglycans are due to the fact that in solution they are strongly hydrated anionic macromolecules. With an external strain, such a compound can go from a randomly coiled to an oriented state.

The intensity of the blood flow can cause such a conformational transition of proteoheparan sulphate, integrated in the membrane of smooth muscle and endothelial cells. This conformational change is combined with an increase in binding sites for $\mathrm{Na}^{+}$ions. When flow is reduced, inner molecular, elastic recoil forces guarantee entropic coiling. Sodium ions are released into the solution.

Heparan sulphate shows $\mathrm{Ca}^{2+}$-dependent conformational transitions. These transitions are correlated with an increased or decreased local mobility of the molecular chains as the correlation times prove. Between 1 and $2.5 \mathrm{mmol} / 1\left[\mathrm{Ca}^{2+}\right]_{0}$, not only are $\mathrm{Ca}^{2+}$ ions bound but $\mathrm{Na}^{+}$ions are also bound in an allosteric, cooperative manner. Above $2.5 \mathrm{mmol} / 1\left[\mathrm{Ca}^{2+}\right]_{0}$, there is a competitive expulsion of $\mathrm{Na}^{+}$ions from their binding sites on the heparan sulphate by $\mathrm{Ca}^{2+}$ ions. These findings support the hypothesis that proteoglycans, integrated in the cell membrane, fulfill the mechano-chemical requirements of a flow sensor.
\end{abstract}

KEY WORDS: Anionic Biopolymers / Heparan Sulphate / Cation Binding / ${ }^{23} \mathrm{Na}^{+}$ NMR Studies / Conformational Changes / Viscoelasticity / Blood Flow Sensor

Macromolecular polyelectrolytes play a decisive part in the control of transmembrane mass transport and cellular information on both sides of the cell membrane. Thus, there is an urgent need for a more integrated approach towards systematically evaluating the structure and function of cytoskeletal proteins and their interactions with the extracellular matrix in membrane biophysics 
and biochemistry. Cytoskeletal and extracellular matrix proteins have many features in common regarding their three-dimensional structure, their interactions and their assembly properties. Within and without the membrane, cell filaments, fibres and more complex supramolecular assemblies are in dynamic equilibrium with molecular building blocks. They exhibit many common structural features and have a high potential for self-assembly. In addition, the two systems are in communication with each other by receptor molecules spanning the plasma membrane and interacting via their extracellular and cytosolic domains with specific compounds.

Biophysical research has made substantial contributions to our present knowledge and understanding of the often complex extracellular matrix. ${ }^{28}$ The three-dimensional structure of the constituent proteins and proteoglycans, the dynamics of their own interplay and interplay with counterions, the thermodynamics of assembly, the mechanisms of regulatory processes, and the composition and molecular organization of complex structures all represent problems that can be approached using a number of biophysical methods. ${ }^{9}$ The present work uses nuclear magnetic resonance (NMR) spectroscopy to study the underlying 'polymerization' or 'aggregation' mechanisms of proteoglycan network formation, the viscoelastic properties of these biopolyelectrolytes and their interaction with small countercations - especially the $\mathrm{Ca}^{2+}$ ion, the participation in ion transport channel formation and in blood flow regulation on a molecular level. ${ }^{3,4,12}$ NMR spectroscopy is a powerful tool for unraveling intra- and intermolecular events and for drawing quantitative conclusions about both the static and dynamic aspects of reversible binding of monoand divalent cations to glycosaminoglycans, proteoglycans and native connective tissue. ${ }^{10}$

When considering the interaction between small cations and the polyanionic macromolecules, the proteoglycans, found in vascular connective tissue as well as in smooth muscle and endothelial cell membranes, attention will be focused on two processes:

1) The regulation of the extracellular ion concentrations in the immediate vicinity of the vascular smooth muscle cell membrane. ${ }^{22-24,29}$ The reversible binding of cations to polyanionic proteoglycans may play an important role in the narrow crevices between the basement and cell membrane.

2) Proteoheparan sulphate, because of its viscoelastic properties and because it is integrated in the smooth muscle and endothelial cell membrane, can be viewed as a suitable flow sensor at the endothelium-blood interface. ${ }^{26}$ It elicits the $\mathrm{Na}^{+}$-dependent, flow-induced vasodilatation in resistance arteries.

\section{EXPERIMENTAL}

\section{Materials}

Common carotid arteries were surgically excised from sacrificed dogs within 3-4 min. Adventitial connective tissue was almost completely removed from both carotid arteries with a microscopically controlled microdissection method. ${ }^{22,24}$ Vascular connective tissue was equilibrated in a modified Krebs solution having the following composition: $\mathrm{Na}^{+} 151.16 ; \mathrm{K}^{+} 4.69 ; \mathrm{Ca}^{2+} 2.52$; $\mathrm{Mg}^{2+} 1.1 ; \mathrm{Cl}^{-} 145.4 ; \mathrm{HCO}_{3}^{-} 16.31 ; \mathrm{H}_{2} \mathrm{PO}_{4}^{-} 1.38$; glucose $7.77 \mathrm{mmol} / 1$ (temp. $37^{\circ} \mathrm{C} ; \mathrm{pH} 7.35$ ). The solution was aerated with a $95 \% \mathrm{O}_{2}-5 \% \mathrm{CO}_{2}$ gas mixture.

For the competition experiments with native adventitial connective tissue, 0.4-1.6 g samples were incubated in a defined volume of a $\mathrm{Ca}^{2+}$-free $\mathrm{Krebs}$ solution. Then defined small amounts of a highly concentrated $\mathrm{CaCl}_{2} \cdot 2 \mathrm{H}_{2} \mathrm{O}$ solution were added to the samples. $\mathrm{pH}$ determinations and readjustments to 7.35 were performed before and after running the NMR spectra.

$\mathrm{Na}^{+}$chondroitin sulphate (Serva, Heidelberg) is composed of $95 \%$ chondroitin sulphate and $5 \%$ protein. ${ }^{11}$ The original material was excluded from Sepharose CL6B but included after papain digestion. Therefore, the preparation was classified as a multi-chain chondroitin sulphate-polypeptide complex (CS-P). Samples were dissolved, unless otherwise stated, in $2 \mathrm{~g}$ of a $0.1 \mathrm{~mol} / \mathrm{l}$ aqueous $\mathrm{NaOH}$ solution to a final concentration of $0.1 \mathrm{~mol} / \mathrm{l}$ for both carboxylate and sulphate groups (i.e. 0.2 monomolar concentration, calculated on the basis of monosaccharide units). 
Native proteoheparan sulphate has a relative molar mass of about $150,000,14 \%$ of which is protein. It has about 3 heparan sulphate side chains in covalent bonding (mol. wt. 35,000-38,000) with an average sulphate content of $0.43 \mathrm{~mol}$ sulphate/disaccharide unit. For the competition experiments with heparan sulphate $e^{4,20}\left(\mathrm{Na}^{+}\right.$salt, average mol. wt. $520 \mathrm{~g} / \mathrm{mol}$ per disaccharide unit) samples were dissolved in a $1.5 \mathrm{ml} \mathrm{Ca}{ }^{2+}$-free $\mathrm{Krebs}$ solution to a $0.1 \mathrm{~mol} / 1$ concentration, calculated on the basis of disaccharide units. $\mathrm{pH}=7.2$ was attained by changing the $\mathrm{O}_{2} / \mathrm{CO}_{2}$ ratio of the gas mixture with which the solutions were aerated before measurement. Exact small amounts of a highly concentrated $\mathrm{CaCl}_{2} \cdot 2 \mathrm{H}_{2} \mathrm{O}$ solution were added to the samples. All inorganic chemicals used were of high purity.

\section{Methods}

The ${ }^{23} \mathrm{Na}^{+}-\mathrm{NMR}$ measurements were performed either on a Bruker WH 90 or a modified Varian XL-100 spectrometer at a resonance frequency of $23.8 \mathrm{MHz}$ or $26.47 \mathrm{MHz}$, respectively. The temperature was $297 \mathrm{~K}$. The transverse relaxation time $T_{2}=1 / R_{2}$ was obtained from the line width $\Delta v_{1 / 2}$ at half height of the high-resolution resonance absorption before and after each $T_{1}$ measurement. The $180^{\circ}-\tau-90^{\circ}$ pulse technique was used to record the longitudinal relaxation time $\mathrm{T}_{1}=1 / \mathrm{R}_{1} . \mathrm{NaB}(\mathrm{Ph})_{4}$ in $\mathrm{CD}_{3} \mathrm{CN}$ was used as the external reference. All relaxation data reported are averages of at least three separate determinations.

\section{Theory}

${ }^{23} \mathrm{Na}$ has a spin quantum number $I=3 / 2$. Therefore, in aqueous solutions, the magnetic relaxation of this nucleus is dominated by quadrupole effects. Assuming that the exchange of $\mathrm{Na}^{+}$ ions between different states is rapid compared to relaxation, and that only two states exist, namely one free (F) and one bound state (B) - or that, if several bound states are possible, one of them dominates by far, it follows:

$R_{\text {obsd }}=p_{F} R_{F}+p_{B} R_{B}$

where $p_{F}$ and $p_{B}$ are the fractions of free and bound ions. Under certain conditions $p_{F} R_{F}$ can be substituted by $R_{0}$, the relaxation rate in a diluted aqueous solution with a very low ion concentration. ${ }^{9}$ By introducing $R_{e x}$ as the difference between the relaxation rates under test conditions and $\mathrm{R}_{0}$,

$\mathbf{R}_{\mathrm{ex}}=\mathbf{R}_{\mathrm{obsd}}-\mathbf{R}_{0}$

equation (1) can be reduced to

$\mathrm{R}_{\mathrm{ex}}=\mathrm{p}_{\mathrm{B}} \mathrm{R}_{\mathrm{B}}$

Unfortunately, the time dependence of the longitudinal and transverse magnetizations for nuclei with a magnetic spin quantum number I $>1$ cannot be represented by a single exponential function, as Hubbard ${ }^{13}$ demonstrated. For nuclei with $\mathrm{I}=3 / 2$, such as ${ }^{23} \mathrm{Na}$, two exponentials are necessary for description. Bull ${ }^{5}$ has established linear approximate equations for longer correlation times $0.2 \leq \tau_{\mathrm{c}} \leq 1.5$ on the basis of the considerations already mentioned, a prerequisite being that chemical exchange takes place much faster than relaxation. These calculations ${ }^{15}$ form the basis of the following equations for two exchanging states, where $\chi$ is the quadrupolar coupling constant, $\tau_{\mathrm{c}}$ the correlation time, and $\omega$ is the Larmor frequency in state B:

$$
\mathrm{R}_{1}=\frac{1}{\mathrm{~T}_{1}}=\mathrm{p}_{\mathrm{F}} \mathrm{R}_{\mathrm{F}}+\mathrm{p}_{B} \frac{2 \pi^{2}}{5} \chi^{2} \tau_{\mathrm{c}}\left[\frac{0.8}{1+4 \omega^{2} \tau_{\mathrm{c}}^{2}}+\frac{0.2}{1+\omega^{2} \tau_{\mathrm{c}}^{2}}\right]
$$


$\mathrm{R}_{2}=\frac{1}{\mathrm{~T}_{2}}=\mathrm{p}_{\mathrm{F}} \mathrm{R}_{\mathrm{F}}+\mathrm{p}_{\mathrm{B}} \frac{\pi^{2}}{5} \chi^{2} \tau_{\mathrm{c}}\left[0.6+\frac{1}{1+\omega^{2} \tau_{\mathrm{c}}^{2}}+\frac{0.4}{1+\omega^{2} \tau_{\mathrm{c}}^{2}}\right]$

Since the relaxation rates can be measured directly, $R_{1,2}$ can be determined by means of equations (2) and (3). Thus, the term $\mathrm{p}_{\mathrm{F}} \mathrm{R}_{\mathrm{F}}$ can be eliminated from equations (4) and (5). The result of this is two equations with only two unknown quantities, $\mathrm{p}_{\mathrm{B}} \chi^{2}$ and $\tau_{\mathrm{c}}$, which can easily be resolved for $\tau_{\mathrm{c}}$. When $\tau_{\mathrm{c}}$ is known, $\mathrm{p}_{\mathrm{B}} \chi^{2}$ can be calculated by renewed insertion into equations (4) or (5). However, $\mathrm{p}_{\mathrm{B}}$ cannot be derived without making further problematic assumptions.

\section{RESULTS AND DISCUSSION}

The discussion of mechanisms of cation binding to connective tissue components abundant in the vascular wall has introduced a completely new kind of consideration into the field of membrane physiology of vascular smooth musculature. ${ }^{25,27,28}$ The ion activities close to the cell membrane depend on the binding properties of anionic biopolyelectrolytes of the basement membrane and connective tissue fibres, which build a tight-fitting sheath around the plasma membrane. Under suitable, non-stationary conditions, a release of cations from or adsorption to the polyanionic macromolecules can lead to transient activity changes in these tiny extracellular tissue compartments between cell membrane, basement membrane and the connective tissue fibres. Such changes may influence transmembrane ionic currents, membrane potential and mechanical tension development.

\section{Cation binding to glycosaminoglycans, proteoglycans and native connective tissue}

The basis of the high ion binding rate is the chemical structure of proteoglycans. A variable number of glycosaminoglycan side chains is combined together with a central protein core to a macromolecule by covalent bonding. ${ }^{3}$ The glycosaminoglycans form a group of polysaccharides, which are sulphated and carboxylated to a greater or lesser extent. Among them, chondroitin sulphate, dermatan sulphate, heparan sulphate, heparin and keratan sulphate have been established as glycosaminoglycan components of proteoglycans.

If the glycosaminoglycans are bound to their natural protein component as they are in native vascular connective tissue, then the ion binding behaviour can be studied under in vivo conditions. ${ }^{23} \mathrm{Na}^{+}$and ${ }^{39} \mathrm{~K}^{+}$NMR measurements indicate that, while monovalent cations exert merely competitive interaction, divalent cations induce a conformational transition changing specifically the affinities for other ion species. ${ }^{11,24} \mathrm{Mg}^{2+}$ or $\mathrm{Ca}^{2+}$ ions cause such a configurational change in the physiologic concentration range which promotes allosteric, cooperative binding of $\mathrm{K}^{+}$or $\mathrm{Na}^{+}$ions, respectively, to vascular connective tissue. In Figure 1 , the ${ }^{23} \mathrm{Na}^{+}$excess relaxation rates are plotted versus the $\mathrm{Ca}^{2+}$ concentration of a Krebs solution at $\mathrm{pH} 7.3$ in the presence of the counteranions of vascular connective tissue. According to normal competition, $R_{2_{\text {ex }}}$ at first decreases with low $\mathrm{Ca}^{2+}$ concentrations up to $0.5 \mathrm{mmol} / 1$. But then $\mathrm{R}_{2}$ increases with further small additions of $\mathrm{CaCl}_{2}$ up to $1.5 \mathrm{mmol} / 1 .{ }^{28}$ Above $1.5 \mathrm{mmol} / 1 \mathrm{Ca}^{2+}$ simple exchange of bound $\mathrm{Na}^{+}$with $\mathrm{Ca}^{2+}$ was observed. Therefore, as in a CS-P solution, $\mathrm{R}_{2}$ increases drastically, which indicates a conformational change. ${ }^{11,21}$ The half-maximal conformational transition is observed with $1.15 \mathrm{mmol} / \mathrm{C} \mathrm{Ca}^{2+}$, i.e. in the physiologically relevant range, considering that half of the serum $\mathrm{Ca}^{2+}$ of $2.5 \mathrm{mmol} / \mathrm{l}$ is bound to proteins.

The increased $\mathrm{R}_{2}$ seen upon $\mathrm{Ca}^{2+}$ additions is referred to an increase in the correlation time $\tau_{\mathrm{c}}$ for bound $\mathrm{Na}^{+}$. This is an approximate measure of the mobility of a molecule or an ion. A raised $\tau_{\mathrm{c}}$ value means less mobility. In Figure 2 , the $\tau_{\mathrm{c}}$ value for $\mathrm{Na}^{+}$increases abruptly in the range $0.5 \mathrm{mmol} / 1<\left[\mathrm{Ca}^{2+}\right]_{0}<2 \mathrm{mmol} / 1$ and then reaches a plateau value. The jump in correlation time cannot be explained by a thermic mobility change of the $\mathrm{Na}^{+}$-matrix macromolecular complex, because polyanions of the connective tissue should influence the correlation times only insignificantly due to their molecular size and the ensuing relative immobility. ${ }^{8,18}$ Therefore, 
Figure 1. ${ }^{23} \mathrm{Na}^{+}$excess longitudinal $(\square)$ and transverse relaxation rates $(O), R_{l_{e x}}$ and $R_{2}$, in dependence on different $\mathbf{C a}^{2+}$ concentrations of a normal Krebs solution $\left(\left[\mathrm{Na}^{+}\right]_{0}=151.2\right.$ mmol/l) containing native vascular connective tissue at $\mathrm{pH}=7.3$. For $0.5 \mathrm{mmol} / 1<\left[\mathrm{Ca}^{2+}\right]_{0}<2 \mathrm{mmol} / 1$ the ratio $\mathrm{R}_{1_{\text {ex }}} / \mathrm{R}_{2_{\text {ex }}}$ is indicative of a conformational transition in the connective tissue polyanions. In addition, the initial rise of the longitudinal relaxation rate signifies allosteric, cooperative $\mathrm{Na}^{+}$binding to the matrix macromolecules.

the most probable explanation of the sudden change of $\tau_{c}$ remains the induction of intra- or intermolecular crosslinking leading to conformational transitions of the polyelectrolyte, to molecular associations, or to both..$^{8,16,18,19,29}$

Besides this conformational transition, the experiment shows an immediate increase of the longitudinal relaxation rate $\mathrm{R}_{1_{\text {ex }}}$ at the very beginning of $\mathrm{Ca}^{2+}$ additions (Figure 1). Obviously, $\mathrm{Na}^{+}$ions are consecutively bound at an allosteric site. Would there be an expulsion of $\mathrm{Na}^{+}$ions by $\mathrm{Ca}^{2+}$ ions, then a continuous decrease of $\mathrm{R}_{1}$ should be discernible as can be seen in comparable $\mathrm{Mg}^{2+}$ competition experiments. ${ }^{28}$ With the possession of both relaxation rates and correlation times, the static contribution to relaxation, i.e. the $\mathrm{Na}^{+}$binding, may be computed.

Indeed, the calculation of $\mathrm{p}_{\mathrm{B}} \chi^{2}$ shows that the $\mathrm{Na}^{+}$ binding increases at once and reaches a maximum of 1.5 times its value with $1.5 \mathrm{mmol} / 1 \mathrm{Ca}^{2+}$ concentration, and decreases only slightly with further increasing $\mathrm{Ca}^{2+}$ concentration (Figure 3). Only above values of $1.5 \mathrm{mmol} / \mathrm{C} \mathrm{Ca}^{2+}$, bound $\mathrm{Na}^{+}$ions exchange for $\mathrm{Ca}^{2+}$ ions which means normal, but weak competition. Another explanation of the slight decrease of $\mathrm{p}_{\mathrm{B}} \chi^{2}$ would likewise be conceivable remembering the previously raised finding, that at least two specific binding sites exist for $\mathrm{Na}^{+}$ions in the proteoglycan. Considering that the allosteric site binds $\mathrm{Na}^{+}$cooperatively due to the $\mathrm{Ca}^{2+}$-induced conformational change, the other site, however, shows normal competition behaviour, it is merely a question of the quantification of both simultaneous processes to enable a simulation of the observed course of the bound fraction. ${ }^{25}$ This means that we can state two extraordinary effects of $\mathrm{Ca}^{2+}$ : on the one hand a conformational change of the macromolecules of vascular connective tissue with rising $\mathrm{Ca}^{2+}$ concentration, on the other hand no $\mathrm{Na}^{+}$competition, but on the contrary a $\mathrm{Na}^{+}$binding to these polyanions. Therefore, the elevation of the $\mathrm{Ca}^{2+}$ concentration in the blood substitute solution does not effect an expulsion of $\mathrm{Na}^{+}$ions from their binding sites, but it induces allosteric $\mathrm{Na}^{+}$adsorption to the polyanionic macromolecules of vascular connective tissue. The question of whether the elevated $\mathrm{Na}^{+}$binding is caused by a conformational change which increases the affinity for $\mathrm{Na}^{+}$ions or the number of binding sites requires further investigation.

What does the binding of monovalent cations to polyanions of the cell membrane exterior surface and of vascular
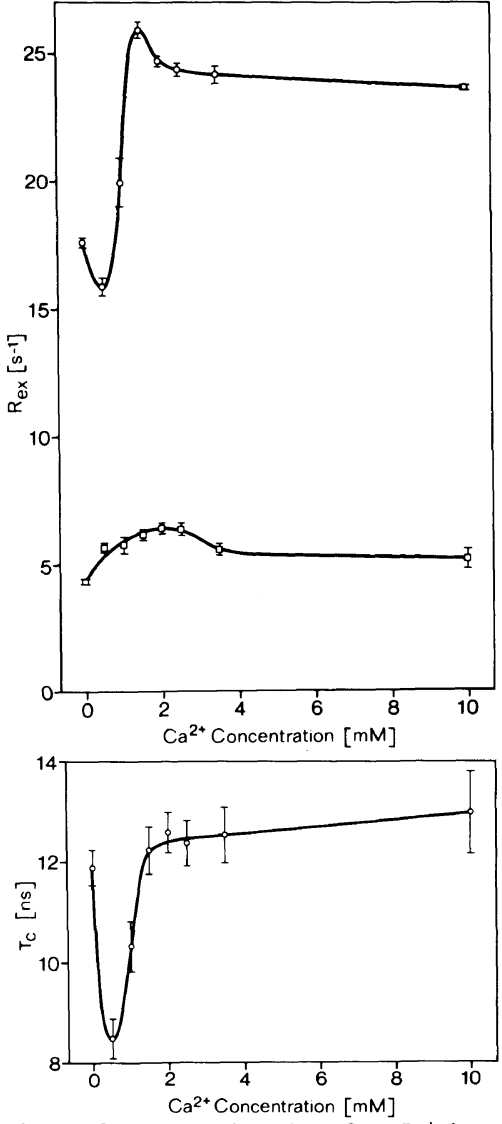

Figure 2. Correlation time for $\mathrm{Na}^{+}$ions bound to native vascular connective tissue as a function of the $\mathrm{Ca}^{2+}$ concentration of a Krebs solution at $\mathrm{pH}=7.3$. The ratio $R_{1_{e x}} / R_{2_{e x}}$ was used in the calculation of $\tau_{c}$.

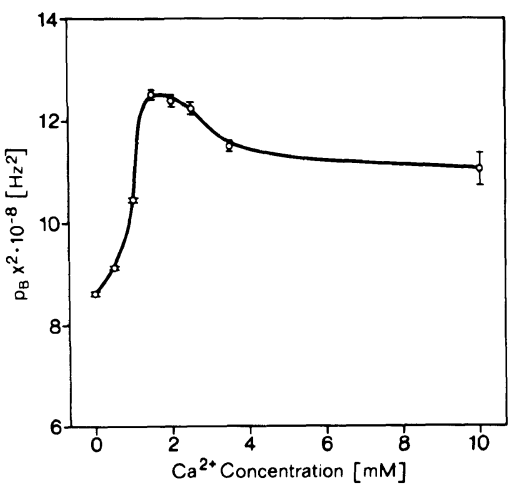

Figure 3. $\mathrm{p}_{\mathrm{B}} \chi^{2}$, the product of the fraction of bound $\mathrm{Na}^{+}$and the squared quadrupolar coupling constant, as a function of the $\mathrm{Ca}^{2+}$ concentration of a $151.2 \mathrm{mmol} / 1 \mathrm{Na}^{+} \mathrm{Krebs}$ solution containing native vascular connective tissue at $\mathrm{pH}=7.3$. 
connective tissue in the immediate vicinity of the cell membrane mean for vasomotor regulations? The geometry of narrow tissue clefts in the interstitial compartment of the vessel wall entails that an increase of extracellular $\mathrm{Mg}^{2+}\left(\mathrm{Ca}^{2+}\right)$ concentration effects a decrease of external $\mathrm{K}^{+}\left(\mathrm{Na}^{+}\right)$ concentration in the vicinity of vascular smooth muscle cell membranes. ${ }^{22,24}$ Thus, the increase of a divalent cation concentration causes a transient hyperpolarization via a fall of the local $\mathrm{Na}^{+}$ and/or $\mathrm{K}^{+}$concentration in the cleft spaces between cell membrane, basement membrane and connective tissue fibres. Inverse effects could be expected after a decrease of the $\left[\mathrm{Mg}^{2+}\right]_{0}$ or $\left[\mathrm{Ca}^{2+}\right]_{o}$ concentration. The effect on vascular tone of such a hyper- or depolarization of vascular smooth muscle cells can easily be demonstrated in the stationary activation curve tension versus voltage. This curve shows that depolarization is connected with contraction, hyperpolarization with relaxation..$^{21,22,24}$ Therefore, the indirect action of divalent effector cations on vascular tone via variations in monovalent cation concentration of $\mathrm{Na}^{+}$and $\mathrm{K}^{+}$presents additional knowledge on vasomotor regulations.

We have seen that nuclear magnetic resonance techniques are a powerful tool to probe into the microdynamic interaction between biopolyelectrolytes and their counterions. It seems that in this analysis we have obtained a consistent picture demonstrating the general applicability of the procedure. We have been able to deduce information on counterion binding, correlation times and quadrupole coupling constants. Certainly, these quantities contain significant information on the physiology of the systems.

\section{Proteoglycan viscoelasticity}

Viscoelasticity is not restricted to a few macromolecular substances, rather it is a property which all such substances attain above their specific softening temperature, provided that they have not already disintegrated. The anionic biopolymers of proteoglycans that are found in vascular connective tissue, and also in the cell membrane of endothelial and smooth muscle cells, belong to this group of substances. ${ }^{4,20}$ If biopolyelectrolytes are subjected to externally applied strain for some time, the stretched molecules will gradually shift and assume their inherent shape in their new position. This phenomenon, whereby the internal stress of the system returns to equilibrium by a change in places of the molecules, is called relaxation. This happens in every flowing liquid, only that in normal, low viscosity liquids relaxation occurs instantaneously so that the elastic recoil is not observed. The viscoelastic substances may therefore be classified as highly viscous liquids. Alternatively, they may be considered as liquids with large relaxation constants because with short periods of deformation they will exhibit elastic properties and with extended periods of external pressure they will show flow characteristics. A typical characteristic is the large difference between the G-moduli of a single substance. The relaxation time depends strongly on structural parameters, e.g. minor changes in the degree of cross linking with any one chain.

The viscoelastic deformation is, in terms of solid body physics, an intramolecular relaxation because it is a flow phenomenon. A cross linked biopolyelectrolyte can be transformed from a randomly coiled to an oriented state by stretching it. With increasing shear stress, the intramolecular and macroscopic viscosity decreases. This is plausible when one considers that the external force applied stretches the polymer chains to a greater or lesser extent (coil deformation). This reduction in entropy induces elastic recoil. The speed of an unrestricted viscoelastic recoil is a measure of the intramolecular viscosity, which can be correlated with this limited flow process consisting of a conformational change in polymer chains. As such it is dependent on the primary chain structure and the temperature.

Figure 4 demonstrates the results of a competition experiment with a multi-chain chondroitin 4-sulphate-polypeptide complex (CS-P) which was derived from native connective tissue. In this investigation the static and dynamic binding properties of $\mathrm{Na}^{+}$ions were studied. The influence on $\mathrm{R}_{2 \mathrm{ex}}$ of an increasing $\mathrm{Ca}^{2+}$ concentration and of elastic energy stored and lost per unit volume of the solution under non-stationary shearing conditions by shaking was measured. It appears that this increase of up to $3.75 \mathrm{mmol} / 1 \mathrm{Ca}^{2+}$ in the solution after it has been added and shaken does 


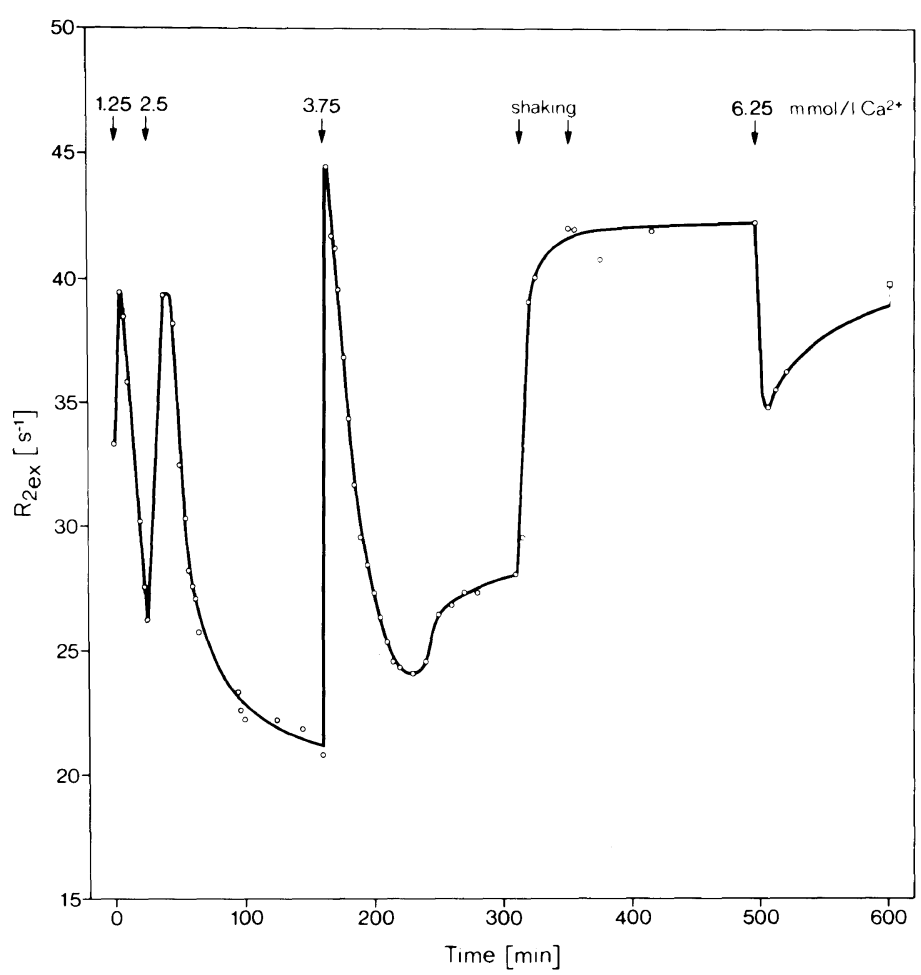

Figure 4. Time dependence of ${ }^{23} \mathrm{Na}^{+}$excess transverse relaxation rate for $0.2 \mathrm{~mol} / 1$ (monosaccharide units) $\mathrm{CS}-\mathrm{P}$ at $\mathrm{pH} 12.2$ with a sodium concentration of $0.3 \mathrm{~mol} / 1$. Additions of $\mathrm{Ca}^{2+}$ ions and/or shaking of the sample (at the arrows) caused an increase in $\mathrm{R}_{2}$ (decrease with $6.25 \mathrm{mmol} / 1 \mathrm{Ca}^{2+}$ ) and then a spontaneous decrease in $\mathrm{R}_{2 \mathrm{ex}}$ (increase with $6.25 \mathrm{mmol} / 1 \mathrm{Ca}^{2+}$ ).

not lead to a reduction in $R_{2_{e x}}$ but regularly to a fast and drastic elevation. Only with $6.25 \mathrm{mmol} / \mathrm{l}$ $\left[\mathrm{Ca}^{2+}\right]_{0}$ competition behaviour appears. The transverse relaxation rate falls. After the addition of $\mathrm{Ca}^{2+}$, the 'envelope curve' initially shows an increase and above $3.75 \mathrm{mmol} / 1\left[\mathrm{Ca}^{2+}\right]_{0}$ a decrease in $R_{2}{ }^{26}$ This curve confirms earlier findings on CS-P9,11,21 and native vascular connective tissue $e^{22,23,25}$ as well as the results from heparan sulphate depicted in Figure 6. This could be interpreted as a conformational change of the macromolecules which is due to a cross linking between different chains owing to the strong ability of $\mathrm{Ca}^{2+}$ to build complexes. This aggregation is expected to affect both $\tau_{\mathrm{c}}$ (reduction of the local mobility) and $\mathrm{p}_{\mathrm{B}} \chi^{2}$ (higher local charge density, increased field gradients). As we have discussed earlier and now documented in Figure 8 for heparan sulphate, not only are $\mathrm{Ca}^{2+}$ ions bound to the polyanions but also $\mathrm{Na}^{+}$ions. These are allosterically-cooperatively bound, in fact to a specific site. A second binding site remains purely competitive and prevails with higher $\mathrm{Ca}^{2+}$ concentrations (cf. $6.25 \mathrm{mmol} / 1\left[\mathrm{Ca}^{2+}\right]_{0}$ ). ${ }^{28} \mathrm{It}$ is clear therefore, that $\mathrm{Na}^{+}$ions are only bound within a relatively small range of $\left[\mathrm{Ca}^{2+}\right]_{0}$. Above this range they will be released again (cf. Figure 8 ).

\section{Proteoheparan sulphate as flow sensor at the endothelium-blood interface}

Figure 4 further shows that with a constant $\mathrm{Ca}^{2+}$ concentration the simple shaking of the solution leads to an increase of $\mathrm{R}_{\mathrm{e}_{\mathrm{ex}}}$. At these low excitation frequencies (similar to physiological frequencies), aggregated multi-chain peptidoglycans in a solution (CS-P) can store much more energy than single-chain peptidoglycan monomers. This indicates that aggregation of proteoglycans greatly enhances network formation. The extent of the network formation in proteoglycan solutions 
is augmented by both an increase in concentration $(0.1 \mathrm{~mol} / \mathrm{l} \mathrm{CS}-\mathrm{P})$ and the proportion of proteoglycan present as aggregates $\left(\mathrm{Ca}^{2+}\right.$ ions). However, the initial network organization, existing in these highly aggregated solutions, is particularly sensitive to disruption at low shear rates. This means that with increasing shear rate ('shaking') the CS-P solution showed shear thinning, a decrease in viscosity which is a macroscopic manifestation of the net loss of the number of intermolecular interactions during shearing. ${ }^{26}$ Thus, shear thinning involves the disruption of the network structure formed by aggregates and at the same time an increase of formerly occluded ion binding sites. ${ }^{17}$ Therefore, the 'shaking' in Figure 4 effects an increase in $R_{e_{e x}}$, which is also an expression of an augmented $\mathrm{Na}^{+}$binding to the anionic polyelectrolyte.

From Figures 2 and 7, the conclusion can be drawn that the sudden changes of $\tau_{\mathrm{c}}$ induce intraor intermolecular cross-linking leading to conformational transitions of the polyelectrolytes and to molecular associations. Such a higher molecular network formation is coupled with an increased viscosity for solutions with ideal statistic coils according to the Einstein-Kuhn ${ }^{6,7,14}$ viscosity law

$[\eta]=\frac{2.5 \sqrt{\mathrm{M}}}{\mathrm{K}_{\rho[\eta]}^{0}}=\mathrm{K}_{[\eta]}^{0} \sqrt{\mathrm{M}}$.

The degree of the rise in viscosity, $\left(\eta_{\mathrm{rel}}-1\right) / \mathrm{c}=\eta_{\mathrm{sp}} / \mathrm{c}$, is a function of the molecular weight $\mathrm{M}$ in such systems. This is based on the characteristic property of coils that their density decreases as their molecular weight increases. One might conclude from this that the $\mathrm{R}_{\mathrm{e}_{\mathrm{e}}}$ increase with elevated $\mathrm{Ca}^{2+}$ concentrations (Figures 1,6 ) could be due to this rise in viscosity. This, however, is most unlikely because Figure 4 demonstrates that the disruption of the network structure with concomitant shear thinning also leads to a dramatic increase in $\mathrm{R}_{2_{\mathrm{ex}}}$. Therefore, greater viscosity cannot be held responsible for the increase in $\mathrm{Na}^{+}$binding.

The deformation of structures, originating in the intermolecular associations of macromolecules, by shear stress - just as the creation of such structures by coil deformation - is an event which can proceed with different speeds. The time constant derived from Figure 4 has a mean value of 4 min. Since $R_{2_{\text {ex }}}$ abruptly rises with shaking, this time constant allows the intervention in cardiovascular control.

The viscoelastic recoil is expressed in the relaxation time, which is a measure of the viscous retardation effect after a sudden application of a constant load on a viscoelastic substance. Ideally, elastic solids, with no internal viscous or frictional dissipations, have zero retardation times. The mean time constant for $\mathrm{R}_{2 \mathrm{ex}}$ relaxation after the addition of $\mathrm{Ca}^{2+}$ ions and shaking, as determined from the protocol in Figure 4, was $25 \mathrm{~min}$. Since the decrease in $\mathrm{R}_{\mathrm{e}_{\mathrm{ex}}}$ and therefore the energy dissipation in the solution start once shaking ceases, this property, which is combined with a fall in the bound $\mathrm{Na}^{+}$fraction, may also be of importance for cardiovascular control.

In rabbit ear resistance arteries, Bevan and Joyce ${ }^{2}$ reported on a sodium dependent, flowinduced dilatation which is endothelium-independent and a function of the rate of infusion. The authors hypothesized that this flow-dilatation is the result of a sodium dependent mechanism in vascular smooth muscle. It seems that their observation neither involves $\mathrm{Na}^{+}$pump activity, nor fast $\mathrm{Na}^{+}$channels, nor $\mathrm{Na}^{+}-\mathrm{Ca}^{2+}$ exchange nor $\mathrm{Na}^{+}-\mathrm{H}^{+}$exchange. Proteoheparan sulphate, a viscoelastic, anionic polyelectrolyte, has been described as a constituent of the vascular smooth muscle cell membrane. ${ }^{4,20}$ The polymer seems to be located at circumscribed sites in the membrane, probably in the vicinity of the $\mathrm{Na}^{+}$channel or it takes part in the channel's molecular structure. The protein core is integrated into the cell membrane while the glycosaminoglycan side chains protrude into the extracellular space (Figure 5). It is quite possible that this proteoglycan, appearing only occasionally (low local concentration), acts as a flow sensor.

In flowing viscous solutions containing molecular coils, these coils will align with the direction of flow. One of the contributing factors to this alignment with flow of molecular coils is any deviation from the perfect sphere. Alignment is more pronounced in diluted solutions of high molecular polymers. This may contribute to a reduction in viscosity, the effect being greater for a steeper flow gradient. This is because the coils in the structurally viscous solution tend to link 
Figure 5. Proteoheparan sulphate as a flow sensor at the endothelium-blood interface. (A) The membrane of an endothelial cell with a $\mathrm{Na}^{+}$channel is represented schematically. The protein core of a proteoheparan sulphate macromolecule is anchored in the cell membrane. Under no flow conditions the viscoelastic polyelectrolyte assumes a random coil form, whereby most of the polyanionic sites undergo intramolecular hydrogen bonding. (B) Blood flow causes a conformational change from the random coil state to the directed filament structure state. This conformational transition effects an unfurling of the glycosaminoglycan side chains and is therefore combined with an increase in binding sites for $\mathrm{Na}^{+}$ions. Counterion migration along the polysaccharide chain is possible.

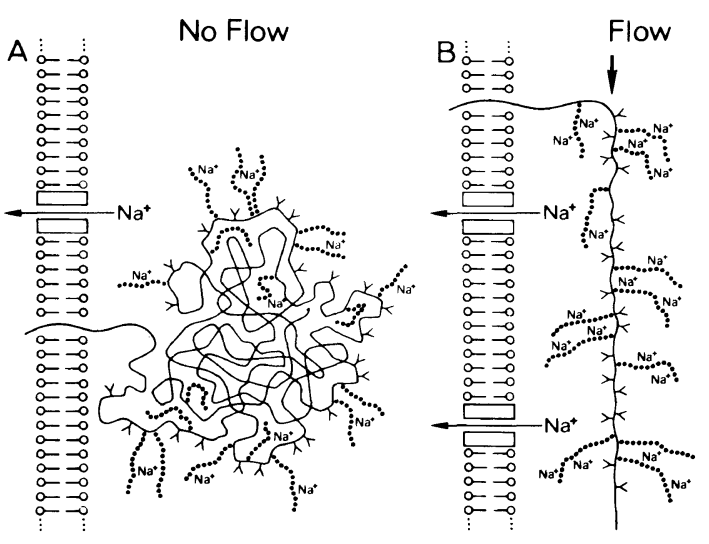

layers of flow. Linkage is least when the coils are aligned. When a flow gradient exists, not only are the coils aligned with the direction of the current but also they become elongated. Inevitably, this results in a more or less pronounced parallel orientation of chain segments. These segments are, of course, not covalently cross-linked but auxiliary valency associations are formed. This conformational change from a random coil to a streamlined filament structure, depending on the flow gradient, is accompanied by an increase of binding sites for counterions. In blood, these are predominantly $\mathrm{Na}^{+}$ions. When the flow is reduced, the viscoelastic recoil forces become effective which then cause a decrease of $\mathrm{Na}^{+}$binding due to a conformational change. The corresponding time constants have already been discussed. Moreover, the $\tau_{\mathrm{c}}$ values in Figure 7 may also be related to counterion migration along a polysaccharide chain or some motion within the chain. ${ }^{11}$ If proteoheparan sulphate is in the immediate vicinity of the $\mathrm{Na}^{+}$channel, or is involved in its formation, then not only $\mathrm{Na}^{+}$binding but also transmembrane $\mathrm{Na}^{+}$flux is plausible. The conformational change, with increased $\mathrm{Na}^{+}$binding, could effect a change in membrane conductance for monovalent cations $\left(\mathrm{K}^{+}\right.$ions) elicited by $\mathrm{G}$ proteins which leads to hyperpolarization. Conversely, with a transmembrane $\mathrm{Na}^{+}$flux an impact acceleration process in a second messenger cascade (e.g. cAMP) is conceivable, which finally produces vasodilatation. $0 \mathrm{mmol} / \mathrm{l}<$ $\left[\mathrm{Ca}^{2+}\right]_{0}<1 \mathrm{mmol} / \mathrm{l}$ and $\left[\mathrm{Ca}^{2+}\right]_{0}>3 \mathrm{mmol} / \mathrm{l}$ diminishes $\mathrm{Na}^{+}$binding (cf. Figure 8 ) and should bring about a reduction of $\mathrm{Na}^{+}$dependent flow-induced vasodilatation. A rise in extracellular $\mathrm{Ca}^{2+}$ concentration from 1 to $2.5 \mathrm{mmol} / \mathrm{l}$ is expected to promote this dilatation.

\section{Proteoheparan sulphate and $\mathrm{Na}^{+}$channels}

Proteoheparan sulphate is not only present in the basement membrane and the extracellular matrix of the vascular smooth muscle cells but is also present as a cell membrane associated or cell membrane integrated proteoglycan in smooth muscle and endothelial cells. ${ }^{4,20,28}$ Cell membrane integrated proteoheparan sulphate, which is in the immediate vicinity of $\mathrm{Na}^{+}$channels of photoreceptor cells, indirectly participates in the visual process. ${ }^{4}$ It brings about the extracellular $\mathrm{Na}^{+}$ion transport of the photoreceptor cell from the inner segment to the outer one which forms a basis of the visual process. A constant extracellular $\mathrm{Na}^{+}$concentration and the maintenance of $\mathrm{a} \mathrm{Na}^{+}$gradient across the cell membrane are prerequisites for this extracellular cation transport. On the basis of their polyanionic structure, the glycosaminoglycan side chains can contribute to a local accumulation of $\mathrm{Na}^{+}$ions. The participation of proteoheparan sulphate in these $\mathrm{Na}^{+}-$ dependent excitation processes suggests that this proteoglycan may be instrumental in the formation of the channel (negative fixed charges). Thus we investigated the $\mathrm{Na}^{+}$binding to this biopolyelectrolyte. The study of the influence of $\mathrm{Ca}^{2+}$ ions on this binding gave further insight into microdynamic polymer changes. Figure 6 shows the $\mathrm{Ca}^{2+}$-induced conformational change in the 


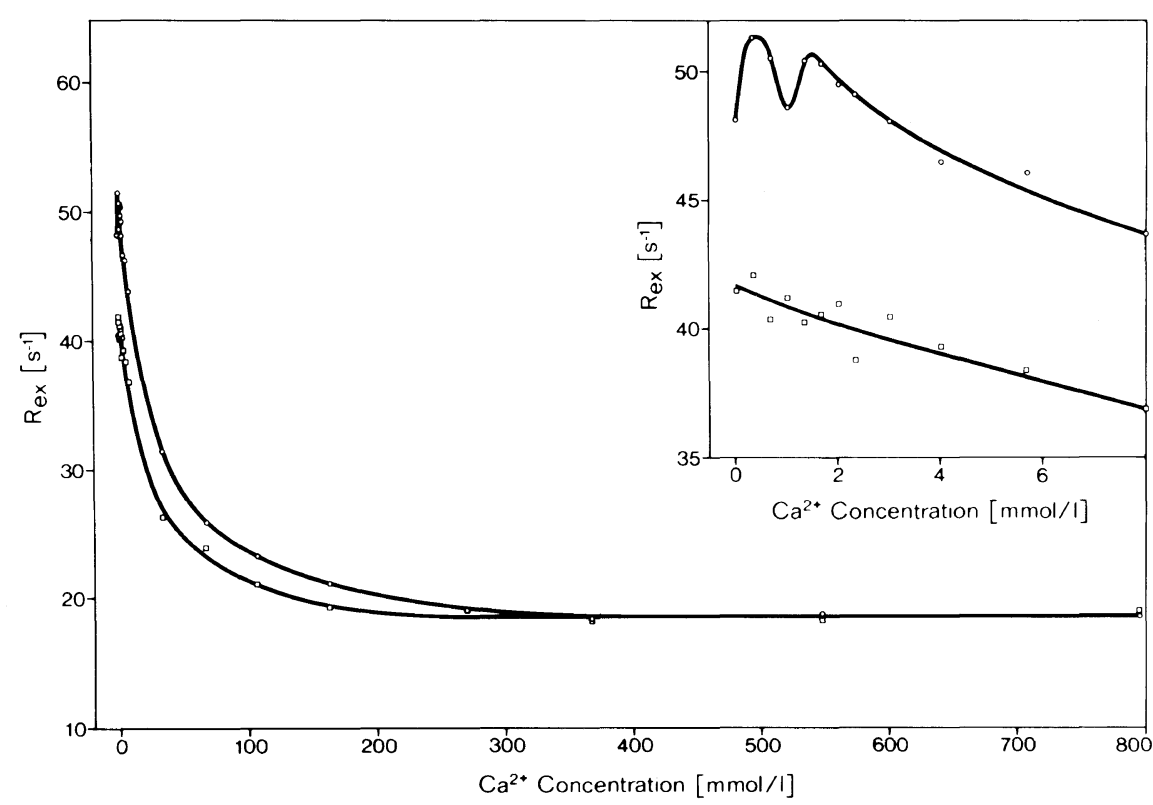

Figure 6. ${ }^{23} \mathrm{Na}^{+}$excess longitudinal $(\square)$ and transverse relaxation rates $(O), R_{1_{\text {ex }}}$ and $R_{2}$, dependent on different $\mathrm{Ca}^{2+}$ concentrations of a normal Krebs solution $\left(\left[\mathrm{Na}^{+}\right]_{0}=151.2 \mathrm{mmol} / \mathrm{l}\right)$ containing $0.1 \mathrm{~mol} / 1$ (disaccharide units) heparan sulphate at $\mathrm{pH}=7.2$.

flow sensor proteoheparan sulphate without applying shear stress. The ${ }^{23} \mathrm{Na}^{+}$excess relaxation rates are plotted against the $\mathrm{Ca}^{2+}$ concentration of a blood substitute solution with a pH of 7.2 containing the polyanions of heparan sulphate $\mathrm{Na}^{+}$salt. It is noticeable that $\mathrm{R}_{\mathrm{ex}}$ in heparan sulphate is about 0.8 times as great as in dermatan 4-sulphate and about 2.2 times as great as in chondroitin 4-sulphate at $\mathrm{pH}=7.4$ and at the same molar concentration for each glycosaminoglycan. ${ }^{10,28}$ When $\mathrm{Ca}^{2+}$ ions in increasing concentrations are continuously bound to the $\mathrm{Na}^{+}$binding sites then $R_{e x}$ should steadily fall. Figure 6 shows a uniform decrease in $R_{i_{e x}}$, i.e. normal replacement of $\mathrm{Na}^{+}$ions by $\mathrm{Ca}^{2+}$ ions. In contrast, $\mathrm{R}_{2}$ increases immediately at the very beginning of $\mathrm{Ca}^{2+}$ additions. Above $1.5 \mathrm{mmol} / 1 \mathrm{Ca}^{2+}$, there was a simple exchange of bound $\mathrm{Na}^{+}$with $\mathrm{Ca}^{2+}$ (normal competition). ${ }^{22,24}$ The drastic increase in $\mathrm{R}_{2}$ indicates a Ca ${ }^{2+}$-linked conformational transition which takes place at two independent binding sites. The binding site with the higher affinity changes its conformation at $0.5 \mathrm{mmol} / 1\left[\mathrm{Ca}^{2+}\right]_{o}$, while the binding site with the lower affinity acquires a new configuration at $1.5 \mathrm{mmol} / 1$.

In this $\mathrm{Ca}^{2+}$ titration experiment, the relaxation was sufficiently non-exponential to permit determinations of the correlation time $\tau_{\mathrm{c}}$ both from the $\mathrm{R}_{\mathrm{e}_{\mathrm{e}}} / \mathrm{R}_{\mathrm{e}_{\mathrm{ex}}}$ ratio and by direct analysis of the transverse decay of magnetization or high-resolution lineshapes. Correlation times obtained from $\mathrm{R}_{1_{\text {ex }}} / \mathrm{R}_{\mathrm{exx}_{\mathrm{ex}}}$, as a function of added $\mathrm{Ca}^{2+}$, exhibit a steep increase up to $1 \mathrm{mmol} / \mathrm{l}$ and then a gradual decrease with higher $\mathrm{Ca}^{2+}$ concentrations (Figure 7). This is consistent with a reduced local mobility of $\mathrm{Na}^{+}$. The variation observed in the correlation time explains most of the variation in ${ }^{23} \mathrm{Na}^{+}$excess relaxation, shown in Figure 6. This is indicative of conformational transitions in the heparan sulphate polyanions.

The static contribution to relaxation, $\mathrm{p}_{\mathrm{B}} \chi^{2}$, may be calculated from both relaxation rates and correlation times. The quadrupolar coupling constant $\chi$ not only depends on the physical constants of the $\mathrm{Na}$ nucleus but also on the magnitude of the electric field gradient at the nucleus. Hence, $\chi$ is partially sensitive to the distance between the small cation and the charges on the polyanion. In this sense $\chi$ is a measure of the strength of the interaction between the polyanion charges and the $\mathrm{Na}^{+}$ions that reside in the bound state. Values of $\mathrm{p}_{\mathrm{B}} \chi^{2}$ for heparan sulphate at different $\mathrm{Ca}^{2+}$ concentrations are given in Figure 8. The decrease of this quantity, seen in the region between 0 


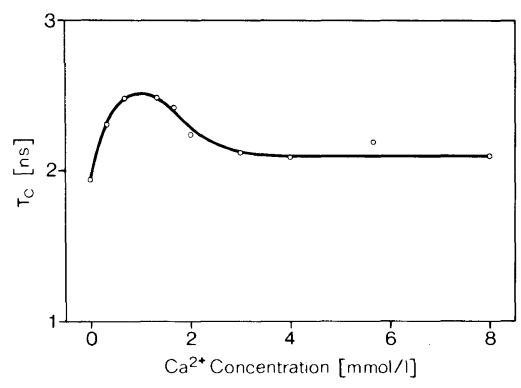

Figure 7. Correlation time for sodium ions bound to heparan sulphate $(0.1 \mathrm{~mol} / \mathrm{l})$ as a function of the $\mathrm{Ca}^{2+}$ concentration in a Krebs solution of $\mathrm{pH}=7.2$. The ratio $R_{1_{e x}} / R_{2}$ was used in the calculation of $\tau_{c}$.

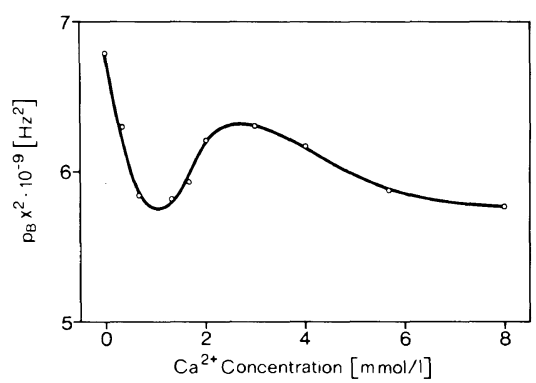

Figure 8. $p_{\mathrm{B}} \chi^{2}$, the product of the fraction of bound $\mathrm{Na}^{+}$and the squared quadrupolar coupling constant, as a function of the $\mathrm{Ca}^{2+}$ concentration of a $151.2 \mathrm{mmol} / 1 \mathrm{Na}^{+}$ Krebs solution containing $0.1 \mathrm{~mol} / 1$ heparan sulphate at $\mathrm{pH}=7.2$.

and $1 \mathrm{mmol} / 1\left[\mathrm{Ca}^{2+}\right]_{0}$, corresponds primarily to a decrease in the fraction of bound ions. Above $1 \mathrm{mmol} / 1\left[\mathrm{Ca}^{2+}\right]_{0}$, the $\mathrm{Na}^{+}$binding increases again and reaches a maximum with $2.5 \mathrm{mmol} / \mathrm{l}$. This means physiologically that, when the $\mathrm{Ca}^{2+}$ concentration is in the normal range between 1 and 2.5 $\mathrm{mmol} / \mathrm{l}, \mathrm{Na}^{+}$ions are increasingly bound to heparan sulphate in an allosteric, cooperative manner (cf. Figure 3). The drop in $\mathrm{p}_{\mathrm{B}} \chi^{2}$ as $\mathrm{Ca}^{2+}$ concentrations increase further is indicative of an exchange of bound $\mathrm{Na}^{+}$ions for $\mathrm{Ca}^{2+}$ ions which means there is normal competition (second, competitive $\mathrm{Na}^{+}$binding site [cf. 25,28]). Therefore, there are two extraordinary effects of $\mathrm{Ca}^{2+}$ : firstly, there are conformational changes of the heparan sulphate macromolecules as $\mathrm{Ca}^{2+}$ levels rise and secondly, there is no $\mathrm{Na}^{+}$competition in the range $1 \mathrm{mmol} / \mathrm{l}<\left[\mathrm{Ca}^{2+}\right]_{0}<2.5 \mathrm{mmol} / \mathrm{l}$, rather a $\mathrm{Na}^{+}$adsorption by these polyanions $\left(\mathrm{Ca}^{2+}\right.$-induced, allosteric $\mathrm{Na}^{+}$binding [cf. $\left.\left.23,25,28\right]\right)$.

With these findings on heparan sulphate some new aspects for the interpretation of $\mathrm{Na}^{+}$ dependent, flow-induced vasodilatation arise:

1) Comparing the results in Figures 7 and 8, even an increasing local mobility, or, at the maximum $\mathrm{Na}^{+}$binding with $2.5 \mathrm{mmol} / 1\left[\mathrm{Ca}^{2+}\right]_{0}$, a nearly constant mobility of the viscoelastic polyelectrolyte is correlated with the increase in $\mathrm{Na}^{+}$binding. These observations are in accordance with the decrease in macroscopic viscosity, when the filament molecules become oriented in the flow gradient with simultaneous $\mathrm{Na}^{+}$binding. The $\mathrm{Na}^{+}$release with $\left[\mathrm{Ca}^{2+}\right]_{0}>$ $2.5 \mathrm{mmol} / \mathrm{l}$ is paralleled by an increase of random coiling and $\mathrm{Na}^{+}$occlusion.

2) A rise in $\left[\mathrm{Ca}^{2+}\right]_{o}$ over and above $2.5 \mathrm{mmol} / 1$ should lead to a reduction of $\mathrm{Na}^{+}$dependent flowinduced vasodilatation. This assumption is confirmed by unpublished results by Bevan $^{1}$.

3) The vasodilatation with an increase in blood flow and a simultaneous $\mathrm{Na}^{+}$binding to the viscoelastic biopolyelectrolyte, proteoheparan sulphate, could be explained by the reduction of negative fixed charges on the outer side of the cell membrane. The result is a membrane hyperpolarization which in turn leads to vasorelaxation by closing voltage-dependent $\mathrm{Ca}^{2+}$ channels.

\section{ACKNOWLEDGEMENTS}

The authors wish to thank Mrs. Ch. Fuhrmann and Mr. H. Ewald for their skilful technical assistance. We are grateful to Mrs. M. Krawczynski for her outstanding work in preparing the illustrations and to Mr. P. Holzner for the photographic work. We are also greatly indepted to Mrs. A. Scheuermann for the translation and editorial elaboration of the manuscript.

\section{REFERENCES}

1. J.A. Bevan, personal communication (unpublished) (1989). 
2. J.A. Bevan, and E.H. Joyce, Physiological saline flow-induced dilation in a resistance artery is associated with an amiloride-sensitive sodium dependent mechanism in the vascular smooth muscle. Circ. Res. (submitted for publication) (1989).

3. E. Buddecke, Vorlesungsreihe Schering, 2, 1-16 (1977).

4. E. Buddecke, and J. Wollensak, Fortschr. Ophthalmol., 86, 502-508 (1989).

5. T.E. Bull, J. Magn. Reson., 8, 344-353 (1972).

6. A. Einstein, Ann. Phys. IV. Folge, 19, 289-306 (1906).

7. A. Einstein, Ann. Phys., 34, 591-592 (1911).

8. R.A. Gelman, and J. Blackwell, Biopolymers, 12, 1959-1974 (1973).

9. H. Gustavsson, G. Siegel, B. Lindman, and R. Ehehalt, "Dynamic Aspects of Biopolyelectrolytes and Biomembranes". Kodansha Ltd., Tokyo, 1982, pp. 3-18.

10. H. Gustavsson, G. Siegel, B. Lindman, and L.-Ȧ. Fransson, FEBS Letters, 86, 127-130 (1978).

11. H. Gustavsson, G. Siegel, B. Lindman, and L.-A. Fransson, Biochim. Biophys. Acta, 677, 23-31 (1981).

12. T.E. Hardingham, H. Muir, M.K. Kwan, W.M. Lai, and V.C. Mow, J. Orthop. Res., 5, 36-46 (1987).

13. P.S. Hubbard, J. Chem. Phys., 53, 985-987 (1970).

14. W. Kuhn, Kolloid Z., 68, 2-15 (1934).

15. B. Lindman, and S. Forsén, "Chlorine, Bromine and Iodine NMR: Physico-chemical and Biological Applications". Springer-Verlag, Berlin, Heidelberg, New York, 1976.

16. M.B. Mathews, "Molecular Biology, Biochemistry and Biophysics". Springer-Verlag, Berlin, Heidelberg, New York, 1975, Vol. 19.

17. M. Nagasawa, "Charged and Reactive Polymers". D. Reidel Publ. Comp., Dordrecht, Boston, 1974, Vol. I, Polyelectrolytes, pp. 57-77.

18. B. Öbrink, and L.-O. Sundelöf, Eur. J. Biochem., 37, 226-232 (1973).

19. D.A. Rees, Biochem. J., 126, 257-273 (1972).

20. A. Schmidt, and E. Buddecke, Exptl. Cell Res., 178, 242-253 (1988).

21. G. Siegel, A. Adler, E. Mildenberger, and A. Walter, Coll. INSERM/CNRS, 124, 101-110 (1984).

22. G. Siegel, M. Bostanjoglo, A. Walter, A.W.H. Jans, and R. Kinne, "Resistance Arteries". Perinatology Press, Ithaca, New York, 1988, pp. 329-335.

23. G. Siegel, A. Walter, M. Bostanjoglo, A.W.H. Jans, and R. Kinne, "Die Anwendung aktueller Methoden in der Arteriosklerose-Forschung". Deutsche Gesellschaft für Arterioskleroseforschung, Tübingen, 1989, pp. 171-182.

24. G. Siegel, A. Walter, M. Bostanjoglo, A.W.H. Jans, R. Kinne, L. Piculell, and B. Lindman, J. Membrane Sci., 41, 353-375 (1989).

25. G. Siegel, A. Walter, M. Bostanjoglo, A.W.H. Jans, and R. Kinne, "Microcirculation - An Update". Excerpta Medica, Amsterdam, New York, Oxford, 1987, Vol. 1, pp. 407-411.

26. G. Siegel, A. Walter, E. Buddecke, A. Schmidt, H. Gustavsson, and B. Lindman, Funktionsanalyse biologischer Systeme (in press) (1991).

27. G. Siegel, A. Walter, A. Jans, and R. Kinne, "Sekundärprävention der Arteriosklerose". Attempto Verlag, Tübingen, 1989, pp. 85-91.

28. G. Siegel, A. Walter, A.W.H. Jans, and R. Kinne, Abhandl. Rhein.-Westf. Akad. Wissensch., 82, 155170 (1989).

29. G. Siegel, A. Walter, and B. Lindman, J. Phys. (Paris), 45, C2-595 - C2-598 (1984). 